\section{AB0927 RELIABILITY AND VALIDITY OF TURKISH VERSION OF FIBROMYALGIA PARTICIPATION QUESTIONNAIRE}

L. Altan ${ }^{1}$, R. Çeliker ${ }^{2}$, I. Ercan ${ }^{3}$, M. Birtane ${ }^{4}$, K. Akgün ${ }^{5}$, C. Zateri ${ }^{6}$, N. Taştekin ${ }^{7}$, A. Rezvani ${ }^{8}$, I. Aktaş ${ }^{9}$, S. Özdolap ${ }^{10}$, E. Dursun ${ }^{11}$, N. Dursun ${ }^{11}$, S. Sarıkaya ${ }^{10}$. ${ }^{1}$ Physical Medicine and rehabilitation, Uludağ University Medical Faculty, Bursa; ${ }^{2}$ Physical Medicine and rehabilitation, Acibadem University, Faculty of Medicine, Istanbil; ${ }^{3}$ Uludağ University Medical Faculty, Bursa; ${ }^{4}$ Trakya University, Faculty of Medicine, Edirne; ${ }^{5}$ Istanbul University, Cerrahpaşa Faculty of Medicine, Istanbul; ${ }^{6}$ Physical Medicine and rehabilitation, Canakkale Onsekiz Mart University, Faculty of Medicine, Çanakkale, ${ }^{7}$ Physical Medicine and rehabilitation, Trakya University, Faculty of Medicine, Edirne; ${ }^{8}$ Physical Medicine and rehabilitation, Bezmialem University, Faculty of Medicine; ${ }^{9}$ Physical Medicine and rehabilitation, Fatih Sultan Mehmet Teaching and Research Hospital, Istanbul; ${ }^{10}$ Physical Medicine and rehabilitation, Bulent Ecevit University, Faculty of Medicine, Zonguldak; ${ }^{11}$ Physical Medicine and rehabilitation, Kocaeli University, Faculty of Medicine, Kocaeli, Turkey

Background: Fibromyalgia (FMS) is a chronic health problem characterized by a wide range of physical and psychological symptoms. There are few high-quality instruments to evaluate the participation and social functioning of fibromyalgia patients. Farin et al. designed the Fibromyalgia Participation Questionnaire (FPQ) as an instrument for measuring the participation and social functioning of FMS patients. The original version of FPQ has been demonstrated to have acceptable internal consistency, reliability and criterion validity.

Objectives: To test reliability and validity of Turkish version of Fibromyalgia Participation Questionnaire (FPQ-T)

Methods: One hundred and eighty-four female fibromyalgia syndrome patients were included in the study. All patients filled FPQ-Turkish (FPQ-T) questionnaire which was obtained by translation from German according to the guideline for the cross-cultural adaptation process.

The patients filled the revised Fibromyalgia Impact Questionnaire (FIQ) and reevaluated FPQ-T two hours later. Internal consistency reliability of FPQ-T was assessed by calculating "if item deleted" using Cronbach alpha and "item-total correction" coefficient for each item of the questionnaire. Consistency of subscales and correlation of test-retest values were assessed. Test-retest values were compared using Wilcoxon test. Criterion validity was measured using FIQ scales by Spearman's rho correlation coefficient.

Results: For internal reliability, Cronbach alpha coefficient was calculated as 0.957 for non-working and 0.958 for working patients. Cronbach alpha values of $0.939,0.871$, and 0.914 were obtained for daily, social, and work life, respectively. Correlation coefficients were 0.888 for daily life, 0.859 for social life, and overall 0.901 in non-working group versus 0.896 in working group. Comparison of scores obtained from test-retest measurements showed no significant difference except for Item-3. Correlation of symptom severity score (SSS) and FPQ-T were $r=0.385$ $(p<0.001)$ and $r=0.390(p<0.001)$ for the non-working and working sub-groups, respectively. Construct validity evaluation showed significant correlation between SSS and FPQ-T.

Conclusions: The results of our study showed that FPQ-T is reliable and valid for assessing participation and social functioning in fibromyalgia patients in our society.

References:

[1] Williams DA, Clauw DJ (2009) Understanding fibromyalgia: Lessons from the broader pain research community. J Pain 10:777-791.

[2] Farin E, Ullrich A, Hauer J (2013) Participation and social functioning in patients with fibromyalgia: development and testing of a new questionnaire. Health Qual Life Outcomes 11:135.

Disclosure of Interest: None declared

DOI: 10.1136/annrheumdis-2017-eular.1710

\section{AB0928 FATIGUE IN FIBROMYALGIA REFLECTS OVERALL BURDEN OF DISEASE}

M. Antivalle, A. Batticciotto, F. Rigamonti, M.C. Ditto, M.C. Gerardi, R. Talotta, A. Mutti, P. Sarzi-Puttini. Rheumatology, L. Sacco University Hospital, Milano, Italy

Background: Fatigue in fibromyalgia is a very common and disabling symptom, being reported by over $75 \%$ of patients. However, the relationship between fatigue and the different manifestations of fibromyalgia has not been convincingly elucidated.

Objectives: Aim of the our work was to study the relationship between fatigue, pain, and somatic symptoms in fibromyalgia.

Methods: 123 patients with fibromyalgia classified according to 2010 criteria were studied, 113 Females and 10 Males, mean age $47.41 \pm 11.21$ years, mean disease duration $6.83 \pm 6.52$ years. Fatigue was assessed by FACIT-Fatigue questionnaire (13 items, score $0-52$, higher values representing less fatigue), and results were correlated to the number of Tender points (TP), to Widespread Pain Index (WPI), to Symptom severity Scale (SSS), and to Polysymptomatic Distress Scale (PDS) values. Correlations were computed by parametric or non parametric methods as appropriate.

Results: Average FACIT-Fatigue score $(22.51 \pm 10.6)$ was lower than the 25th percentile of the general population (35), and was not correlated to age or to disease duration $(p>0.05)$. FACIT-Fatigue showed statistically significant inverse
Fig. 1. Left panel: FACIT-Fatigue score according to the presence or absence of individual somatic symptoms.

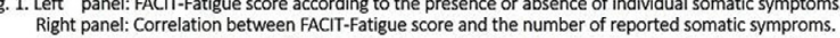
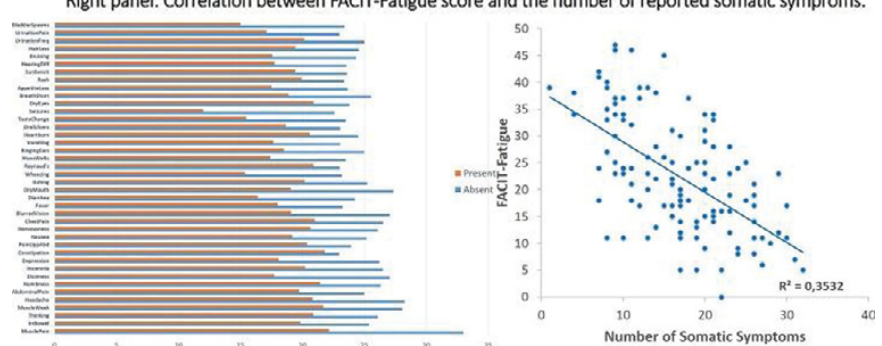

correlations with the number of tender points $(r=-.303, p=0.001)$, WPI score $(r=-0.329, p<0.001)$, SSS score $(r=-0.651, p<0.001)$, PSD score $(r=-0.522$, $p<0.001)$, and with the total number of somatic symptoms $(r=-0.594, p<0.000)$ (Fig. 1, right panel). Furthermore, for each of the 40 somatic symptoms suggested by 2010 criteria, the presence of the symptoms was associated with higher levels of fatigue (Fig 1, left panel).

Conclusions: The results of our study confirm that fatigue is a prominent feature of fibromyalgia. Higher levels of fatigue reflect higher levels of widespread pain, and a higher burden of somatic symptoms.

Disclosure of Interest: None declared

DOI: 10.1136/annrheumdis-2017-eular.6534

\section{AB0929 BALANCE IN FIBROMYALGIA IS NOT RELATED WITH LOWER LIMB STRENGTH}

P. Serra-Añó, M. Aguilar-Rodríguez, S. Cortés-Amador, G.V. Espí-lópez, N. Sempere-Rubio. Physical Therapy, University of Valencia, Valencia, Spain

Background: Postural control, that depends on many sensory contributors and motor skills, is altered in people with fibromyalgia (FM) ${ }^{1-3}$. Knowing those contributors that could be impaired in this population is important to design an appropriate balance therapy.

Objectives: Due to the fact that people with FM use to present a strength loss ${ }^{7}$, our main goal was to explore the relation between postural control and lower limb strength in this population. Further, the sensory inputs contributors to the postural control were assessed.

Methods: A cross-sectional study was conducted in a sample of $40 \mathrm{FM}$ patients. A force platform was used to assess postural control under five bipedal conditions: i) eyes-open (EO); ii) dual task (recalling a typical day in their life) (DT); iii) eyesclose (EC); iv) eyes-open over a foam (FEO); v. eyes-close over a foam (FEC). Three variables, "Ellipse", "RMS" and "Sample Entropy" (SampEn), were recorded (for both directions). Further, maximal quadriceps (qdc) and hamstring (hmsg) isometric strength were assessed using a dynamometer. Spearman correlations were conducted to establish the relationship between postural control and strength and a repeated-measures MANOVA, to analyze differences between conditions. Results: When EO and DT (performed with eyes open) were compared, no significant differences were obtained. However when patients closed their eyes, an increase in ellipse and RMS_AP and a decrease in variability were obtained. The same was true when the tests were performed over a foam (altering proprioception), Table 1.

Table 1. Comparison of sensory inputs results

\begin{tabular}{lccccc}
\hline & Ellipse $\left(\mathrm{mm}^{2}\right)$ & RMS_AP $(\mathrm{mm})$ & RMS_ML $(\mathrm{mm})$ & SampEn_AP & SampEn_ML \\
\hline EO & $295.66(460.93)$ & $5.58(3.66)$ & $2.46(2.30)$ & $0.74(0.14)$ & $0.90(0.10)$ \\
DT & $388.92(530.23)$ & $5.77(4.22)$ & $2.79(2.18)$ & $0.67(0.15)$ & $0.86(0.13)$ \\
EC & $508.18(801.69)^{1}$ & $6.77(3.94)^{12}$ & $3.08(2.04)$ & $0.65(0.15)^{1}$ & $0.85(0.14)^{1}$ \\
FEO & $815.32(981.44)^{123}$ & $7.63(4.19)^{12}$ & $4.81(3.04)^{123}$ & $0.61(0.14)^{12}$ & $0.79(0.10)^{123}$ \\
FEC & $1425.54(1291.53)^{1234}$ & $10.87(4.20)^{1234}$ & $6.48(2.95)^{1234}$ & $0.53(0.11)^{1234}$ & $0.69(0.13)^{1234}$ \\
\hline
\end{tabular}

EO: eyes-open; DT: dual task; EC: eyes-close; FEO: Eyes-open over a foam; FEC: Eyes-close over a foam; Superscript 1,2, 3, 4: Significant differences with test $1,2,3$ and 4 , respectively $(p<0.05)$.

Furthermore, no significant correlations $(p>0.05)$ were observed between strength and balance except for a weak significant correlation between hmsg strength and RMS_AP $\left(r_{s}=-0.33, p<0.05\right)$ in the EC test.

Conclusions: Postural control worsens in FM people when some sensory inputs are altered or missed. Further, there is no correlation between lower limb strength and balance in this population.

\section{References:}

[1] Akkaya N, Akkaya S, Atalay NS, Acar M, Catalbas N, Sahin F. Assessment of the relationship between postural stability and sleep quality in patients with fibromyalgia. Clin Rheumatol. 2013;32(3):325-331.

[2] Jones KD, King LA, Mist SD, Bennett RM, Horak FB. Postural control deficits in people with fibromyalgia: a pilot study. Arthritis Res Ther. 2011;13(4):R127.

[3] Russek LN, Fulk GD. Pilot study assessing balance in women with fibromyalgia syndrome. Physiother Theory Pract. 2009;25(8):555-565.

[4] Góes SM, Stefanello JM, Homann D, Lodovico A, Hubley-Kozey CL, Rodacki $\mathrm{AL}$. Torque and muscle activation impairment along with insulin resistance are associated with falls in women with fibromyalgia. J Strength Cond Res Strength Cond Assoc. 2016; 30(11), 3155-3164. 